\title{
Organizational Resilience: An Investigation of Key Factors that Promote the Rapid Recovery of Organizations
}

\author{
Kikuchi Azusa \\ Kyushu University, Japan \\ Yamaguchi Hiroyuki \\ Kyushu University, Japan
}

\section{Doi:10.5901/ajis.2013.v2n9p188}

\begin{abstract}
The purpose of this study is to identify psychological factors that facilitate quick restoration at organizational scale from temporary trauma or distress due to unexpected catastrophic events. The research is based on the food manufacturing company located in Onagawa, Miyagi prefecture, greatly suffered from The Great East Japan Earthquake in 2011. Questionnaire survey on all workers was conducted followed by interview with Managing Directors of the company. The interview results suggest that a critical factor of resilience is high levels of organizational commitment among the workers at contingency event. A result from the questionnaire survey supports the improvement of organizational commitment due to higher resilience at individual level as teamwork of workers is developed in the events. These results suggest that education or training that aim at promoting team work under difficult situation are important to facilitate organizational resilience.
\end{abstract}

\section{Introduction}

The purpose of this study is to identify those psychological factors that help an organization to recover quickly from temporary dysfunction or disorder triggered by an unexpected catastrophic event. This research is based on a food manufacturing company located in Miyagi Prefecture, Japan, which experienced significant damage in The Great East Japan Earthquake in 2011.

The ability to survive and thrive in turbulent times such as an economic downturn, natural disasters and global military conflict has become a key concern for companies over the last decade. Traditional infrastructure models have focused on building a robust risk management system to minimize the probability of and impact from unexpected negative events. However, such a system can limit urgent decision-making and its execution when a company faces unexpected negative events. Therefore, the flexibility and adaptability of organizations have become more important in an environment of rapid change (Kitamura, 2011). The concept of "resilience", which is described as the ability to be flexible and to recover from significant negative events, is currently receiving widespread attention.

In Japan, the concept of resilience has received greater attention since The Great East Japan Earthquake that caused extensive damage on 11 March 2011. Many organizations suffered direct and indirect damage or were affected in some way by the disaster. This experience has given them opportunity to acknowledge the risk of unexpected negative events and to evaluate their management structures and systems.

In addition, a number of organizations directly or indirectly damaged by the earthquake have found it difficult to secure sufficient resources to rebuild and are not yet operational. In contrast, those that have successfully achieved the rapid rebuild of their businesses with limited resources: food manufacturing company " $A$ " is one of them. Company $A$ is based in Onagawa, Miyagi Prefecture, which suffered extensive damage in the earthquake; nevertheless, company $\mathrm{A}$ restarted its operation only 10 days after the earthquake and has made a large contribution to the local community and residents.

There are number of crucial procedures and resources required for organizations to recover from unexpected negative events. It is management's role to secure the means of recovery such as money, physical resources and the restoration of its technical systems. However, in such circumstances, it is the efforts of on-site workers that are key to the recovery of organizations. When considering organizational resilience, environmental factors in terms of financial and physical resources are not the only essential elements, psychological factors including the mental status of on-site workers and atmosphere or communication among them must also be considered. Despite the importance of these 
factors, most previous studies have not empirically clarified how those psychological factors influence an organization's recovery process.

Hence, this research analyses company A's successful rebuild process as an example of the facilitation of organizational resilience and emphasises the psychological factors in play. The aim of this analysis is to clarify the key factors that support the rapid recovery of an organization after an unexpected negative event. As part of our preliminary research, a questionnaire survey was given to all employees at company A, followed by an interview with the managing director, Mr T.

\section{Organizational Resilience}

The term "resilience" essentially refers to the physical ability to return to one's original state, elasticity or flexibility. The concept of resilience is used in many academic disciplines and fields and received much attention after the 2011 Tohoku Earthquake. In addition, there are a number of definitions and concepts for resilience. In the field of psychology, the definition by Masten, Best and Garmezy (1990) is widely used: resilience is "the process of, capacity for, or outcome of successful adaptation despite challenging or threatening circumstances". In Japan, Oshio, Nakatani, Kaneko and Nagamine (2002) consider resilience as "mental restoration ability" and characterized as the "internal ability owned by individuals who can flexibly cope with and recover from temporary mental illness as a result of unexpected contingency".

Ergonomic studies have also recently integrated the concepts of resilience from a macro perspective. There is the chance for any organization, irrespective of its size or type, to confront a variety of negative events, either internally by human error, technically due to a system collapse or externally as a result of a natural disaster or the failure of a corporate partner. The importance of resilience falls on the ability of overall recovery in terms of flexibility in coping with the event and how to minimize damages and recover from such sudden and major negative events. In ergonomics, the concept of resilience engineering focuses on how to optimize resilience with the ability of a system to adjust, monitor, preserve and sustain its functioning (Hollnagel, Woods \& Leveson, 2006). In contrast to psychological studies, resilience engineering is more focused on short-term recovery. This is because a quick recovery is necessary to minimize costs resulting from damage (Kikuchi \& Yamaguchi, 2012).

Ergonomics looks at the overall circumstance or situation of an organization whereas psychological studies focus instead on the mental recovery of individuals. A combination of the advantages of both ergonomics and psychology enables a broad approach regarding organization resilience from a psychological perspective. This research describes organizational resilience as the resilience retained by an organization that enables rapid recovery from an unexpected negative event that has caused a temporary catastrophe for an organization. This is considered different from the concept of individual resilience widely discussed in psychological studies.

The subject in this research, company $A$, is an ideal example of an organization that possesses a high level of organizational resilience. This is demonstrated by its quick recovery from significant damage and the recommencement of its operation after the earthquake.

\section{Preliminary Investigation}

\subsection{Objective}

An interview with Mr T, the on-site leader when the earthquake struck, was conducted to examine the essential factors that support organizational resilience in the face of a major unexpected negative event.

\subsection{Procedures}

A 3-hour interview was conducted with Mr T at the premises of company A in December 2012. The following topics were covered during the interview: (a) the scale of damage from the earthquake, (b) specific post-earthquake actions and procedures, (c) main duties performed as leader, (d) employees' roles, (e) factors that led to rapid recovery, and (f) future activities. The interview was recorded with an IC recorder as authorized by $\mathrm{Mr} \mathrm{T}$. It was then documented and classified by two psychology researchers and two ordinary peoples.

\section{Results}

\subsection{Examination of factors that support rapid recovery}


Mr T stated that the positive proactive approach of the employees was an important factor, stating, "our staffs performed uncompromisingly and appropriately under the circumstances. The stress among them in turn resulted in more effective teamwork." He was impressed with the employees' teamwork, even though they also personally experienced the disaster. Therefore, "teamwork" was used as a key factor in this study.

Mr T continued "We had to do what was necessary at the time and there was no point in worrying. I strongly believed that our company's recovery could directly contribute to the recovery of Onagawa. All our staffs were confident in the company's recovery and there was a great deal of concern among them. The confidence of the staff was absolutely an essential factor in this recovery process". He considered that the effectiveness of the employees' efforts came from the strong belief in company A. This suggests that an employee's high evaluation the company's resilience is an important factor. Therefore, the term "evaluation of organizational resilience" is used as a second key factor.

In addition, Mr T repeatedly stated, "to achieve the recovery of the organization, there were crucial problems to resolve such as securing financial and physical resources and the maintenance of technical and environmental systems. However, if the staff were not with us, these would have no meaning. It was most important that staff remained on board and worked toward the organization recommencing its operations. Although layoffs may be a temporary solution cost wise, the workforce is a crucial factor in the recovery on a long-term basis."

From the interview above, the factors that correlated with the recovery of company A can be summarized as follows:

(a) committed to and encouraged each other under difficult circumstances, thus strong teamwork emerged from the disaster; (b) strong belief and confidence in the ability to recover, thus an evaluation of organizational resilience; and (c) these factors in turn resulted in a greater commitment by employees to company A. This summary describes Mr T's views regarding the important factors following the earthquake. However, to further assess these factors it is necessary to obtain employees' perspective and opinions. Thus, this research included a questionnaire survey to examine the process model where teamwork establishes organizational commitment with the recognition of organizational resilience.

\section{Main Research}

\subsection{Methods}

The research was conducted in early February 2013 with all 205 employees, excluding the chief executive and managing directors. Of those 172 respondents (response rate: 83.90\%), effective samples from 167 respondents were collected. The effective response rate was $81.46 \%$ [female: 85 ; male: 82 ; average age: $37.63(S D=13.64)$; average duration at work: 6.03 years $(S D=6.75]$.

\subsection{Structure of questionnaire}

\subsubsection{Face sheet:}

A voluntary response survey was prepared to avoid triggering memories of the disaster, as this could have been distressing for the respondents. It was emphasized in the survey that respondents could leave a question unanswered if the question produced negative mental effects. The contact details of the surveyor were clearly stated if after-care was required due to the contents of the questions. For confidentiality, to ensure that respondents would answer all questions truthfully, each completed questionnaire sheet was placed in an envelope and then sealed. To ensure further confidentiality, the sheet also clearly indicated that the survey results would only be used for the research purpose stated by the researchers.

1. Teamwork measure

Using the teamwork scale determined by Misawa, Sasou and Yamaguchi (2009), four scales with the highest correlation factor loadings were selected. The statements were written in past tense to resemble conditions at that time.

2. Organizational resilience evaluation measure

An original organizational resilience evaluation measure was created, comprised of six categories such as, "We have the ability to tackle any problem due to unexpected events without losing motivation among the team."

3. Organizational commitment measure 
Using the organizational commitment measure in Takagi, Ishida and Masuda (1997), the three factor loadings with the highest correlations were used.

Respondents could choose from 5 response options for all questions: " $1=$ Not applicable at all" to " $5=$ Very true".

\section{Results and Discussion}

\subsection{Factor Structure:}

The unweighted least squares method (promax rotation) was used for factor analysis on each measure.

\subsubsection{Teamwork measure factors}

Factor analyses were performed on Team Orientation, Team Leadership and Team Process.

1) Team Orientation: As a result of the factor analysis, a two-factor structure was found. Another factor analysis excluding the item "comfortable with the environment", which scored a lower factor loading, found the same two-factor structure as that determined by Misawa et al., (2009). Factor 1 was "Orientation for completing tasks" with a Cronbach's alpha of 0.85, and Factor 2 was "Orientation for interpersonal relations", with a Cronbach's alpha of 0.81 . These scores revealed acceptable levels of internal consistency.

2) Team Leadership: A two-factor structure was also found for this factor. Factor 1 was "Job directions" with a Cronbach's alpha of 0.86 and Factor 2 was "Concern for interpersonal relations" with a Cronbach's alpha of 0.86 . These scores revealed acceptable levels of internal consistency.

3) Team Process: A two-factor structure was found here after retesting by excluding a total of 4 items: those with the lowest and highest factor loading scores between specific factors. Factor 1 was "Information sharing" with a Cronbach's alpha of 0.85 . Factor 2 was "Clarification of task" with a Cronbach's alpha of 0.93 and Factor 3 , "Monitoring and coordination", had a Cronbach's alpha of 0.81 . The final factor, Factor 4, "Mutual feedback" had a Cronbach's alpha of 0.88 . These scores revealed acceptable levels of internal consistency.

\subsubsection{Organizational resilience evaluation measure}

A one-factor structure was found. Further details regarding the questions asked and Cronbach's alphas are provided in Table 1.

Table 1. Categories of Organizational Resilience Evaluation measure $(\alpha=.94)$

\begin{tabular}{lc}
\hline 1. We can commit aggressively to work as a team after motivation among team decreased due to unexpected catastrophic events. & .88 \\
2. We can encourage each other when disappointed for own abilities after facing unexpected catastrophic events & .86 \\
3. We are confident to believe in ourselves to overcome from unexpected catastrophic events & .86 \\
4. We can quickly restore motivation with team members after mental suffering from contingency events & .85 \\
5. We encourage each other against mental fatigue in some members due to unexpected events & .83 \\
6. We have the ability to tackle any problem due to unexpected events without losing motivation among the team & .82 \\
\hline
\end{tabular}

\subsubsection{Organizational commitment measure}

Unlike the structure determined by Takagi et al., (1997), a three-factor structure was found because one factor included both normative and continuance elements. The items were set as follows: Factor 1: "Affective commitment" with a Cronbach's alpha of 0.87; Factor 2: "Normative commitment" with 0.89; and Factor 3: "Intrinsic commitment" at 0.85. These scores revealed acceptable levels of internal consistency.

\subsection{Descriptive statistics of each variable}

Descriptive statistics and the correlation coefficient of each variable are shown in Table 2. The average value of all the variables excluding "Clarification of task" was higher than 3 , which is considered to be sufficient. 
Table 2. Mean, Standard Deviation, Correlation Coefficient of Variables

\begin{tabular}{|c|c|c|c|c|c|c|c|c|c|c|c|c|c|}
\hline & $M$ & $S D$ & 1 & 2 & 3 & 4 & 5 & 6 & 7 & 8 & 9 & 10 & 11 \\
\hline 1. Orientation for completing tasks & 3.22 & .79 & & & & & & & & & & & \\
\hline 2. Orientation for interpersonal relations & 3.50 & .82 & $.67^{* *}$ & & & & & & & & & & \\
\hline 3. Job directions & 3.19 & .78 & $.63^{3 *}$ & $.69^{* 8}$ & & & & & & & & & \\
\hline 4. Concern for interpersonal relations & 3.23 & .85 & $.73^{* *}$ & $.77^{* 8}$ & $.79^{* *}$ & & & & & & & & \\
\hline 5. Monitoring and coordination & 3.46 & .83 & $.57^{8 *}$ & $.60^{* 8}$ & $.62^{* *}$ & $.72^{* *}$ & & & & & & & \\
\hline 6. Clarification of task & 2.87 & .95 & $.53^{s *}$ & $.53^{* 8}$ & $.61^{* *}$ & $.69^{* *}$ & $.68^{* *}$ & & & & & & \\
\hline 7. Information sharing & 3.33 & .93 & $.64^{3 *}$ & $.61^{* 8}$ & $.66^{* *}$ & $.76^{* *}$ & $.68^{* *}$ & $.68^{* *}$ & & & & & \\
\hline 8. Mutual feedback & 3.37 & .99 & $.54^{* *}$ & $.57^{* 8}$ & $.66^{4 *}$ & $.65^{* *}$ & $.61^{* *}$ & $.62^{* *}$ & $.70^{* *}$ & & & & \\
\hline 9. Organizational resilience evaluation & 3.29 & .82 & $.52^{3 *}$ & $.57^{* 8}$ & $.62^{* *}$ & $.68^{* *}$ & $.52^{* *}$ & $.50^{* *}$ & $.58^{* *}$ & $.45^{* *}$ & & & \\
\hline 10. Affeective commitment & 3.23 & 1.00 & $.59^{3 *}$ & $.58^{* 8}$ & $.57^{* *}$ & $.57^{* *}$ & $.38^{* *}$ & $.45^{* *}$ & $.36^{* *}$ & $.37^{* *}$ & $.45^{* *}$ & & \\
\hline 11. Normative commitment & 3.46 & 1.12 & $.48^{* *}$ & $.43^{* 8}$ & $.44^{* *}$ & $.46^{* *}$ & $.32^{* *}$ & $.42^{* *}$ & $.30^{* *}$ & $.35^{* *}$ & $.35^{* *}$ & $.77^{* *}$ & \\
\hline 12. Intrinsic commitment & 3.21 & .93 & $.52^{* *}$ & $.45^{* 8}$ & $.47^{* *}$ & $.46^{* *}$ & $.28^{* *}$ & $.46^{* *}$ & $.36^{* *}$ & $.41^{* *}$ & $.44^{* *}$ & $.73^{* *}$ & $0^{* 3}$ \\
\hline
\end{tabular}

\subsection{Examination of relevance between each variable}

Structural equation modeling was conducted using Amos Graphics 17.0 to examine the relevance between teamwork, organizational resilience evaluation and organizational commitment. The results are shown in Fig. 1.

A time series hypothesis model was created based on the theoretical background: "Effective teamwork following the earthquake improved the organizational resilience evaluations of the employees, which in turn facilitated organizational commitment". A full-model analysis was performed by setting teamwork as an independent variable, organizational resilience evaluation as a parameter and organizational commitment as a dependent variable. As a result, the hypothetical model supported the statement that organizational commitment improves under such conditions. The AGFI value was low at 0.85 but acceptable overall.

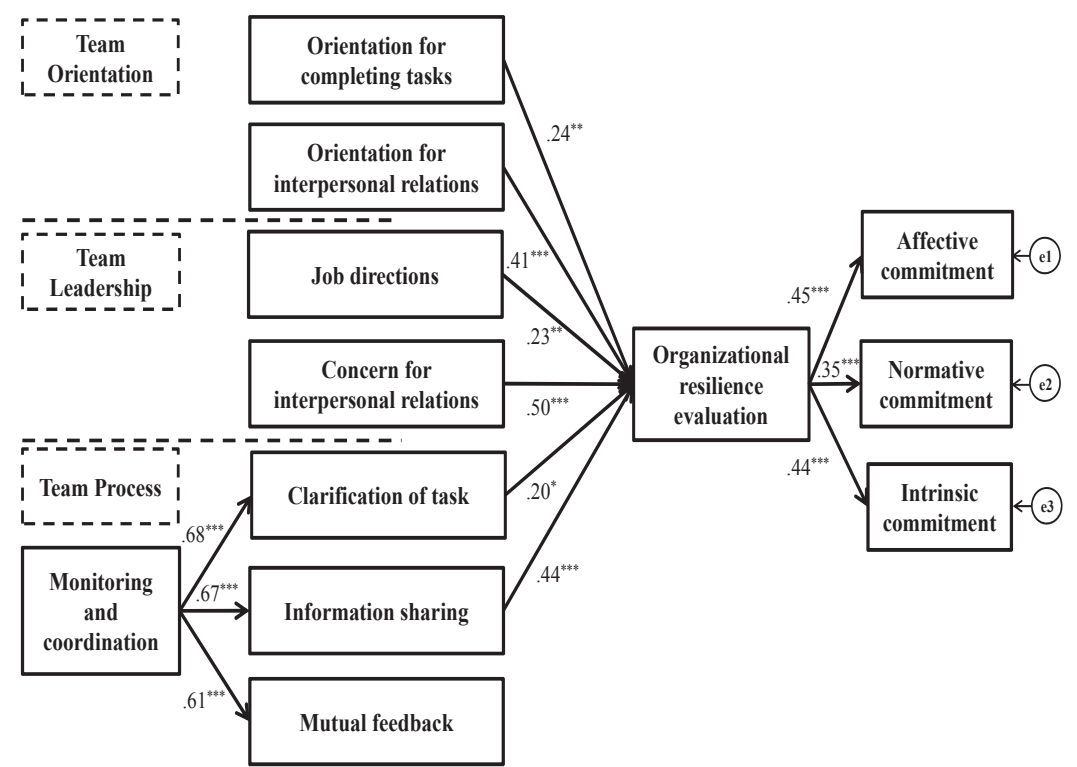

Fig. 1 The result of Structural Equation Modeling ${ }^{* * *} p<.001,{ }^{* *} p<.01,{ }^{*} p<.05$ 


\subsubsection{Relationship between Team Orientation and Organizational Resilience}

The results show that both variables, Orientation for completing tasks $(\beta=0.24, P<0.01)$ and Orientation for interpersonal relations $(\beta=0.41, P<0.001)$ facilitated organizational resilience. As per the interview results, the employees assessed that since the earthquake company A had been motivated towards the achievement of its goals and recognized that they enjoyed an atmosphere where employees respected each other's strengths. These factors contributed to improve company A's organizational resilience.

\subsubsection{Relationship between Team Leadership and Organizational Resilience}

Both variables, Job directions $(\beta=0.23, P<0.01)$ and Concern for interpersonal relations $(\beta=0.50, P<0.001)$ were found to facilitate organizational resilience. This was because the employees actively clarified their own roles, gave instructions accordingly and listened to each other to build motivation among them.

\subsubsection{Relationship between Team Process and Organizational Resilience}

Monitoring and coordination improved Clarification of task $(\beta=0.68, P<0.001)$, Information sharing $(\beta=0.67, P<0.001)$ and Mutual feedback $(\beta=0.61, P<0.001)$. Monitoring and reciprocal adjustment by confirming each other's roles, the sharing of knowledge and information and providing feedback led to an improvement in organizational resilience. In addition, it was demonstrated that both variables, Clarification of task $(\beta=0.20, P<0.01)$ and Information sharing $(\beta=$ $0.44, P<0.001)$ facilitated organizational resilience. This shows that to achieve rapid recovery after an unexpected negative event, both the separation of duties and the active sharing of knowledge and information within an organization are crucial factors.

\subsubsection{Relationship between Organizational Resilience and Organizational Commitment}

Organizational resilience improved all the hypostatic factors of organizational commitment (affective commitment: $\beta=$ $0.45, P<0.001$; normative commitment: $\beta=0.35, P<0.001$; intrinsic commitment: $\beta=0.44, P<0.001$ ). This result suggests that the strong confidence of the employees in the rapid recovery of their company led to an improvement in organizational commitment on various levels.

\section{Conclusion}

In company A, teamwork was effectively established following a devastating earthquake in 2011 , with confidence in its recovery high among team members. These perceptions led to greater active commitment toward recovery. Organizational resilience as a result of effective commitment was not only influenced by the sharing of knowledge and information but also via interpersonal intentionality and consideration. It was demonstrated that under an extremely difficult environment, that strong communication and the creation of a cooperative environment can effectively overcome the challenges and generate organizational commitment.

The confidence and opportunity to face and tackle challenges with other colleagues or managers created feelings that each individual can practically and emotionally provide commitment and contribute to the organization. Conventional methods used to overcome such difficulties include the revision of rewards or human resources. However, this did not apply to this case where there was no guaranteed business or contracts. In this sense, the results from this research are highly suggestive.

$\mathrm{Mr} \mathrm{T}$, as top-level management, paid attention not only to securing physical/environmental resources and maintaining technical systems but also to the mental state of his employees and made conscious decisions regarding their welfare. This approach has effectively contributed to the facilitation of organizational resilience. Moreover, in response, employees stepped up to the plate and worked hard to rebuild company $\mathrm{A}$. It is these factors that led to the rapid recovery and recommencement of company A's operations.

This research only examined one organization that achieved a high degree of organizational resilience in trying circumstances. Thus, further research on other organizations is required to assess the facilitation process of organizational resilience. 


\section{References}

Hollnagel, E., Woods, D. D., \& Leveson, N. (2006). Resilience Engineering: Concepts and Percepts. Ashgate Publishing Co.

Kikuchi, A. \& Yamaguchi, H. (2012) A clue to Synthetic Understanding of Resilience in Organization: Recomposition by crossing two dimensions of time-series and different of objects. Journal of Human Interface Society: human interface, 14 (2), pp.103-108

Kitamura, M. (2011) Higashinihonniokeru "souteigai"to soshikino resilience. (Emergency and Resilience of Organization in East of Japan.) Japan Ergonomics Society Kanto Branch 41th Conference, pp. 16-17

Masten, A. D., Best, K. M., \& Garmezy, N. (1990). Resilience and development: Contributions from the study of children who overcome adversity. Development and Psychology, 2, 425-444.

Misawa, R., Sasou, K., \& Yamaguchi, H. (2009) Development of the Teamwork Measure for Nursing Teams. Japanese journal of social psychology, 24 (3), pp.219-232

Oshio, S., Nakatani, M., Kaneko, M., \& Nagamine, K. (2002) Negative na dekigoto karanotatchinaoriwomichibikushinritekitokusei; seishintekikaihukuryokusyakudo nosakusei. (The psychological properties that promote bounce back from negative states.) The Japanese journal of counseling science, 35, pp.57-65.

Takagi, H., Ishida, M., \& Masuda, K. (1997) Kaisyaningenwomeguruyouinkouzou.

(The factor structure of company man.) Tao, M. (edit) Kaisyaningennokenkyuu. (The study of company man.) , Kyoto University Press. 